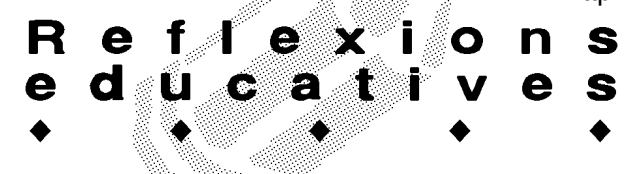

\title{
ALGUNES CONSIDERACIONS SOBRE L'ESTAT ACTUAL DE L'ENSENYAMENT DE LA HISTÒRIA, LA GEOGRAFIA I LA RESTA DE CIÈNCIES SOCIALS
}

\author{
Antoni Santisteban Fernández. Àrea de Didàctica de les Ciències Socials
}

Quan es va iniciar el debat sobre la Reforma Educativa, ara fa més de deu anys, una part del professorat que vam participar en aquestes primeres reflexions consideràvem, per davant de tot, que l'important era com podríem millorar la nostra pràctica educativa a partir de dos aspectes que s'havien de tenir en compte: a) les experimentacions que s'estaven portant a terme a Catalunya i a la resta de l'Estat Espanyol, concretades en materials curriculars innovadors i una concepció democràtica de la cultura; b) les noves idees i els nous plantejaments sobre el procés d'ensenyament i aprenentatge, que van coincidir, per a un sector del professorat, en un enfocament sociocultural, en un marc constructivista i crític, on situar els nous currículums d'història, geografia i ciències socials, i que ens permetia tenir una teoria on poder situar la nostra pràctica.

El debat sobre la Reforma no ha estat sempre el que esperàvem, sinó que s'ha convertit, massa sovint, en un debat molt pobre des del punt de vista educatiu, dominat per les qüestions corporatives, burocràtiques i institucionals i polítiques. Malgrat tot, hem de reconèixer que el balanç d'aquests anys és positiu, pel que significa d'avenç global. Només cal veure l'augment considerable de publicacions, noves revistes, investigacions i materials curriculars sobre l'ensenyament de la historia, geografia i ciències socials.

\section{Situació actual de la didàctica de les ciències socials}

En els últims temps hem vist com creixia la literatura dedicada a la didàctica de les ciències socials. Per exemple, si observem els dos últims anys, s'han publicat nombroses aportacions importants al voltant de l'ensenyament de les ciències socials (per exemple, Benejam i Pagès, 1997; Trepat i Comes, 1998; VVAA, 1998), tenint en compte l'àmbit de l'Estat espanyol, ja que als Estats Units, Anglaterra, França o Itàlia, per exemple, el creixement encara ha estat més important. A més a més, des d'àrees afins també s'ha publicat una gran quantitat de materials sobre temes d'educació en valors o sobre l'ensenyament a partir de noves tecnologies, que en moltes ocasions fan referències concretes a l'ensenya- ment de la història, la geografia o al coneixement social.

En el camp de la investigació, el Boletín Informativo de la Asociación Universitaria del Profesorado de Didáctica de las Ciencias Sociales (núm.3, juny de 1997), recollia un total de trenta-vuit tesis doctorals sobre l'ensenyament de la geografia, la història o les ciències socials, de les quals la majoria havien estat llegides als anys noranta i solament vuit als vuitanta. Els dos últims anys s'han presentat, segons el mateix butlletí, set investigacions sobre l'ensenyament de les ciències socials, que, encara que tenen diferent valor, algunes representen un pas significatiu per al coneixement teòric i pràctic de l'educació social (per exemple, Travé, 1997; Batllori, 1998).

\section{Els materials curriculars}

Un altre aspecte que reflecteix l'evolució positiva del coneixement sobre com ensenyar i aprendre ciències socials, és l'augment considerable de propostes programàtiques i de materials curriculars, amb una justificació teòrico-pràctica ben fonamentada i ben estructurada. $A$ més a més, aquestes propostes en moltes ocasions són el fruït d'un treball en equip, del professorat més inquiet per la renovació educativa a les ciències socials. Pioners d'aquests grups són el grup d'Història 13-16 i Germania. Exemples actuals són tots els materials publicats per la Federación Icaria, que recull els treballs de diversos grups de tot l'Estat Espanyol: Asklepios de Cantabria, Aula Sete de Galícia, Cronos de Salamanca, Ínsula Barataria de l'Aragó, Ires d'Andalusia, Pagadi de Navarra (per exemple, Ínsula Barataria, 1994).

La majoria d'aquests materials estan pensats des d'una perspectiva sociocultural, de l'educació crítica, i el professorat ja no és un intermediari o transmissor de coneixements, sinó el facilitador dels aprenentatges, amb un paper important en la construcció del coneixement. S'ha de tenir en compte que els materials curriculars massa sovint es presenten com a neutrals en el procés d'adquisició del coneixement, el que és una falàcia, ja que la selecció de continguts o de materials té una càrrega ideològica important i respon a unes 


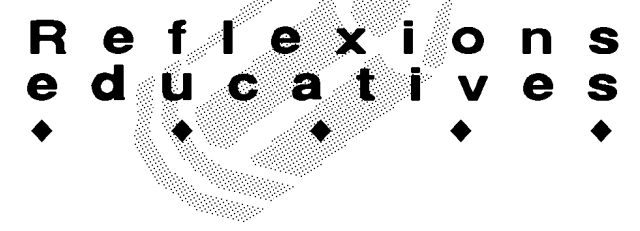

intencions educatives; pensem, per exemple, en els mapes (vegeu la figura 1).

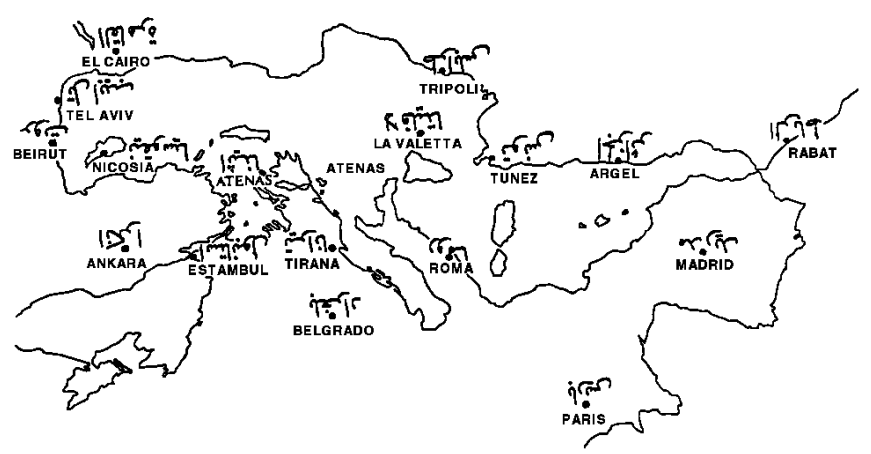

Figura 1. Proposta de lectura del mapa de la Mediterrània per tal de superar la lectura subliminal de superioritat/inferioritat deguda a la convencional posició nord/sud de les representacions.

Uns materials, coordinats per Benejam i Pagès (1997), fan una lectura interessant del currículum de secundària de ciències socials. Fan un plantejament del procés d'ensenyament $\mathrm{i}$ aprenentatge com a regulació $\mathrm{i}$ autoregulació. Presenten diversos temes dividits en quatre grans apartats: societat $i$ territori, societats històriques i canvi en el temps, el món actual i la vida moral i la reflexió ètica. Cada tema té la mateixa estructura, comença amb la reflexió general d'un especialista, continua amb la justificació didàctica de la selecció i de la seqüenciació dels continguts, i amb un formulari de comunicació d'objectius i d'autoregulació per a l'alumnat. El desenvolupament dels continguts inclou explicacions, documents i materials per a l'alumnat i per al professorat, activitats d'avaluació i d'autoavaluació. La seva originalitat radica també en el fet que no es presenten un seguit de temes que no tracten el programa de manera exhaustiva, sinó que els temes són independents i es poden escollir en funció de les necessitats del centre cada curs. Cada any s'ofereixen temes nous alternatius, com a col-lecció ampliable.

\section{El debat sobre el coneixement social}

Al costat de tots aquests materials curriculars nous, hi ha un debat teòric que acompanya la pràctica? Sembla que sí, però els canvis no estan afectant tot el professorat, sinó una part significativa que de moment no podem quantificar. És molt possible que sense un plantejament de Reforma Educativa el debat sobre el coneixement social a l'educació secundària hauria avançat en la mateixa direcció, però s'ha de reconèixer que la llei ha fet accelerar alguns processos. D'altra banda, el camí per a la millora i la renovació de l'educació social no acaba amb la Reforma, sinó que té una autonomia pròpia i unes expectatives que estan per sobre de situa- cions conjunturals. Què queda d'aquell primer debat sobre la pràctica educativa? Què ha significat de millora el debat sobre la Reforma Educativa per a l'ensenyament de les ciències socials? Quins són els aspectes fonamentals que preocupen a qui s'interessa pels estudis socials? Les respostes a totes aquestes preguntes assenyalen les problemàtiques essencials sobre l'ensenyament i l'aprenentatge de les ciències socials. Aquestes qüestions han deixat de ser obstacles per avançar i s'han convertit en els nuclis fonamentals de reflexió, de debat i de definició del coneixement social, és a dir, en els aspectes essencials sobre els quals cal aprofundir per a la millora de la intervenció didàctica a l'aula.

¿Quins són els nuclis essencials en el debat sobre l'ensenyament i l'aprenentatge de la historia, la geografia i les altres ciències socials? Analitzarem els tres aspectes que ens semblen més importants a l'actualitat: a) Les finalitats: per a què aprendre ciències socials al segle $X X I$ ? b) La selecció i l'organització dels continguts: què hem d'ensenyar? c) La comunicació a l'aula: negociar, compartir, formar i formar-se, intercanviar. Farem un petit recorregut per aquests temes apuntant algunes innovacions i algunes preguntes.

\section{Les finalitats}

Les finalitats de l'ensenyament de les ciències socials constitueixen una reflexió important que ha de fer el professorat, ja que la seva concreció afectarà tota la resta de components del currículum: continguts, estratègies, avaluació, etc. Sobre les finalitats recauen una sèrie de pressions clàssiques a l'educació social: la tradició religiosa, l'educació nacionalista, les contradiccions entre les expectatives socials i les finalitats educatives, i la nostra pròpia condició, com a mestres, d'actors $\mathrm{i}$ espectadors socials. Existeixen tres grans tradicions en l'ensenyament de les ciències socials: com a "transmissió de la ciutadania", com a "disciplines científiques" sense diferència dels estudis socials, i com a "investigació reflexiva", seguint les propostes de Dewey (1985).

Segons l'epistemologia de la ciència aplicada a l'ensenyament de les ciències socials, existeixen tres tradicions que conviuen a l'actualitat a les aules en les pràctiques del professorat de secundària: la positivista, la humanista i la crítica. Aquestes tradicions donen lloc a tres concepcions del currículum. La primera és la del currículum tècnic, quan el professorat és un intermediari entre l'administració i el seu alumnat, copiant el currículum oficial o utilitzant un llibre de text que l'interpreta amb fidelitat. La segona és la del currículum pràctic, seguit per una part del professorat que prioritza l'acció 


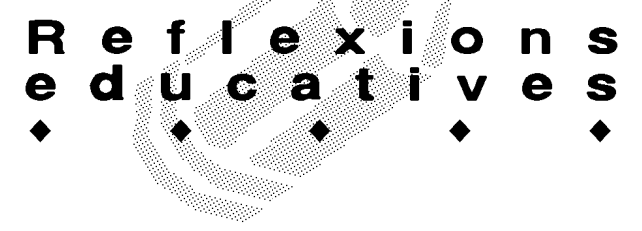

per sobre de la reflexió teòrica i que ha correspost, durant algun temps, a l'escola activa i als moviments de renovació pedagògica. Per últim, el currículum crític reinterpreta el procés d'ensenyament i aprenentatge com un procés dinàmic, on el professorat és una peça fonamental en la decisió de per què, què i com ensenyar i avaluar, i l'activitat de l'alumnat es dirigeix a la reconstrucció dels seus propis aprenentatges.

Per definir una proposta de finalitats per a l'ensenyament de les ciències socials hem de fer una anàlisi crítica de la nostra societat. Si haguéssim de concretar les característiques destacades del nostre món podrien ser:

a) el procés de globalització econòmica i cultural;

b) la flexibilitat de les estructures econòmiques i la inflexibilitat de les estructures socials;

c) el relativisme del coneixement produït per l'enfonsament de la racionalitat contemporània;

d) el canvi tecnològic continuat i incomprensible;

e) la diversitat i la descentralització, cosa que no es tradueix sempre en més llibertat;

f) la sobrevaloració de la rendibilitat i de la competitivitat, que donen Iloc a l'obsessió per l'eficàcia;

g) les transformacions de les relacions humanes, la inestabilitat emocional i la necessitat de l'autoconeixement i l'autoacceptació;

h) la mitificació de la imatge i de l'espectacle, de la simulació per sobre de la realitat per la influència de la televisió;

i) la desestructuració de la comprensió del temps i l'espai, deguda als canvis en la tecnologia comunicativa i de transports;

j) per últim, la incertesa davant el futur, fet que comporta una gran dificultat per imaginar futurs positius possibles.

Davant d'aquesta situació, la nostra proposta per a l'ensenyament de les ciències socials es basa en sis camps d'actuació: finalitats culturals, científiques, pràctiques, intel-lectuals, per al desenvolupament personal, i per a la intervenció social. Les finalitats culturals s'han de traduir en la reproducció de la cultura, però també en la seva reinterpretació i, per tant, en la seva transformació. Les finalitats científiques signifiquen reconstruir el coneixement de l'alumnat, transformar el seu saber vulgar en saber intel-lectual. Les finalitats pràctiques s'han de dirigir cap a la utilització dels aprenentatges socials per a la vida quotidiana, és a dir, fer dels estudis socials estudis funcionals, útils i que l'alumnat entengui la seva importància per comprendre i participar en el seu món social. Les finalitats intel-lectuals han de concretar-se en la formació del pensament social, pensament crític creatiu, d'anàlisi social i d'elaboració d'alternatives. Les finalitats per al desenvolupament personal fan incidència en l'autoconeixement $\mathrm{i}$ l'autonomia personal, l'autoconcepte i l'autoregulació com a habilitat social, Per últim, les finalitats per a la intervenció social són la síntesi i la conseqüència lògica de la resta de finalitats, són les finalitats per a l'educació democràtica, per a la participació social, és a dir, en últim terme aprenem ciències socials per intervenir socialment i millorar el nostre món.

\section{La selecció de continguts}

Una de les dificultats més importants d'ensenyar ciències socials fa referència a les qualitats del seu coneixement. Els continguts de les ciències socials són difícils de definir, canviants, d'una gran abstracció i relativitat. Els conceptes socials -canvi, democràcia, cultura-, necessiten d'un cert consens per a la seva explicació, són conceptes que provoquen interpretacions diferents i definicions distintes. Els procediments de treball amb el coneixement social han de facilitar la comprensió dels continus canvis, que qüestionen cada vegada el nostre coneixement actualitzat de la societat. Els valors socials són inherents al mateix coneixement social, van units a l'estudi de l'aprofitament d'un riu o de l'urbanisme d'una ciutat, de l'estudi d'un conflicte històric o de la distribució de la població.

La història, la geografia i la resta de ciències socials -sociologia, antropologia, política, economia, dret-, revisen i augmenten el seu coneixement amb una rapidesa que fa impossible arribar a tots els seus sabers; per tant es requereix una selecció acurada dels seus continguts, és a dir, ensenyar allò més rellevant i a la vegada més significatiu i funcional de la societat a l'alumnat, sense que es perdi la seva importància científica des de la perspectiva de les ciències socials. És, potser, l'element més important de l'àmbit científic de la didàctica de les ciències socials. En els últims temps hi ha hagut algunes aportacions essencials per avançar en aquest terreny, de les quals n'analitzarem, breument, cinc: a) la transposició didàctica; b) els conceptes clau; c) la teoria de l'assimilació; d) els mapes conceptuals; e) la teoria de l'elaboració.

a) Per ensenyar ciències socials el professorat realitza un procés de selecció i seqüenciació de continguts, d'organització i presentació del coneixement social per al seu aprenentatge. Aquest procés de selecció i adaptació s'anomena transposició didàctica i es basa, en principi, en la impossibilitat d'ensenyar les ciències socials tal i com les elabora la persona experta. En aquest sentit es requereix la transformació del saber científic o saber savi en saber escolar o saber ensenyat. Aquesta transformació es veu condicionada pel saber profes- 


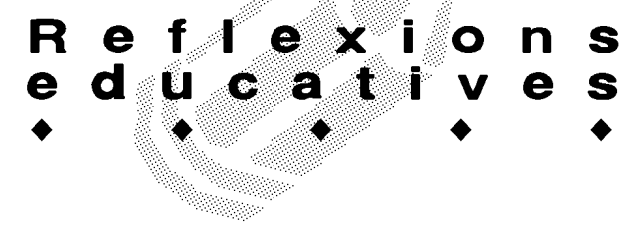

sional, social i didàctic, i pel saber del mateix alumnat i per les seves condicions a l'hora dels aprenentatges.

b) Els conceptes clau han estat utilitzats per alguns autors com a organitzadors del currículum de ciències socials, amb una gran eficàcia. Aquests conceptes clau són els conceptes més importants acceptats per a cada una de les ciències socials. Són conceptes que construïm tota la vida, com per exemple els conceptes de diversitat, poder o canvi. Són conceptes que es poden aplicar a qualsevol realitat, per exemple el poder a la família, a l'escola, a la ciutat, etc. Són conceptes que es relacionen amb determinats problemes socials, com per exemple el conflicte amb les diferències culturals o econòmiques. Són conceptes que configuren una proposta conceptual unitària per a un ensenyament transdisciplinari de les ciències socials. En una investigació realitzada per professorat de diverses universitats espanyoles en què vam poder participar, es van proposar els conceptes clau que apareixen al quadre al costat d'altres propostes (vegeu la figura 2).

c) Per organitzar els continguts de ciències socials s'han d'establir alguns criteris prioritaris. El primer és que es tinguin en compte els coneixements previs de l'alumnat. El segon, que els continguts que s'han d'ensenyar siguin coherents amb la ciència que s'està ensenyant. El tercer, que el coneixement de l'alumnat sigui ampliat i assegurat amb progressió i continuïtat, prioritzant un currículum en espiral. El quart, que les temàtiques que es tractin siguin equilibrades, de manera que no hi hagi temes o coneixements sobrevalorats.

La Teoria de l'Assimilació d'Ausubel distingeix tres tipus d'estructuracions del coneixement. Subordinada, quan a partir d'idees generals es deriva un procés de diferenciació i especificació progressiva. Supraordenada o inductiva, quan a partir de categories específiques es dedueixen significats més generals i inclusors. Combinatòria, quan a partir d'idees preexistents es dedueixen idees noves amb la mateixa categoria o jerarquia.

d) Per a l'organització de continguts són molt interessants els mapes conceptuals, que ens ajuden a estructurar les idees fonamentals que s'han d'ensenyar. Aquests mapes conceptuals, que també es poden utilitzar com a estratègies d'aprenentatge amb l'alumnat, són hereus de les teories sobre els esquemes de coneixement i sobre els conceptes clau. Els mapes conceptuals poden aplicar-se a una etapa, cicle o a un tema concret. Donada l'especificitat del coneixement social són instruments de gran utilitat per donar sentit a les xarxes

\begin{tabular}{|c|c|c|c|}
\hline \multirow{2}{*}{$\begin{array}{l}\text { LA NOSTRA } \\
\text { PROPOSTA }\end{array}$} & \multirow{2}{*}{$\begin{array}{l}\text { Altres conceptes que es } \\
\text { dedueixen dels conceptes } \\
\text { clau de la columna anterior }\end{array}$} & \multicolumn{2}{|c|}{ PROPOSTES D'ALTRES AUTORS } \\
\hline & & Taba & Gross \\
\hline Identitat-alteritat & $\begin{array}{l}\text { Autoconeixement } \\
\text { Autoacceptació } \\
\text { Tolerància }\end{array}$ & & \\
\hline Diferenciació & $\begin{array}{l}\text { Diversitat } \\
\text { lgualtat-Desigualtat }\end{array}$ & Diferències & \\
\hline Racionalitat & $\begin{array}{l}\text { Causalitat } \\
\text { Complexitat } \\
\text { Relativitat }\end{array}$ & Causalitat & Causalitat múltiple \\
\hline Valors i creences & $\begin{array}{l}\text { Judicis } \\
\text { Intencionalitat }\end{array}$ & $\begin{array}{l}\text { Valors } \\
\text { Tradició }\end{array}$ & $\begin{array}{l}\text { Elecció } \\
\text { Valors } \\
\text { Avaluació }\end{array}$ \\
\hline Canvi-continuïtat & & $\begin{array}{l}\text { Canvi cultural } \\
\text { Modificació }\end{array}$ & Canvi social \\
\hline Comunicació & $\begin{array}{l}\text { Intercanvi } \\
\text { Conflicte }\end{array}$ & Conflicte & $\begin{array}{l}\text { Assimilació } \\
\text { Conflicte i administració } \\
\text { de conflictes }\end{array}$ \\
\hline Interrelació & $\begin{array}{l}\text { Interdependència } \\
\text { Cooperació }\end{array}$ & $\begin{array}{l}\text { Cooperació } \\
\text { Interdependència }\end{array}$ & Interacció \\
\hline Organització social & $\begin{array}{l}\text { Poder } \\
\text { Llibertat } \\
\text { Responsabilitat }\end{array}$ & $\begin{array}{l}\text { Poder } \\
\text { Control social }\end{array}$ & $\begin{array}{l}\text { Poder } \\
\text { Institucions }\end{array}$ \\
\hline
\end{tabular}

Figura 2. Taula de conceptes clau de ciències socials. 


\section{กำ}

conceptuals.

e) La Teoria de l'Elaboració és d'una gran utilitat per al disseny de seqüències didàctiques. Per explicar-la els seus autors comparen la seqüenciació d'una unitat de continguts amb una cambra de cinema; primer s'ofereix un plànol general del paisatge, després es fan plànols de detall amb el zoom i es retorna al plànol general, que veurem d'una manera diferent, enriquida. Aquesta teoria, per tant, proposa presentar en principi una panoràmica general del tema a l'alumnat, per després treballar cada una de les seves parts i tornar, cada vegada, al conjunt per ampliar la seva visió. És un diàleg continu d'allò més general a allò més concret i del més simple al més complex. El primer i l'últim plànol general s'anomenen "epítoms", inicial i final, i cada una de les parts detallades "elaboracions".

\section{La comunicació a l'aula}

La comunicació que es dóna a l'aula és el baròmetre que ens indica quin tipus de model educatiu es gestiona en el seu interior, per regular les relacions o les interaccions entre les diferents persones que hi conviuen. Aquesta comunicació és en gran part oral i en gran part simbòlica. Una part important de la comunicació es canalitza a través dels materials curriculars que regulen la feina que han de realitzar els nois i noies a la classe. La majoria d'aquests materials acostumen a ser escrits i, entre aquests, abunden els textos descriptius o explicatius, però trobem a faltar els textos argumentatius que justifiquin amb raons de pes els seus arguments, i tenint en compte també les raons dels altres. Un treball molt interessant en aquest sentit és el de Benejam i Quinquer (1998). Aquestes autores distingeixen diferents habilitats cognitivolingüístiques respecte als textos escrits, en l'aprenentatge de les ciències socials: descriure, definir, comparar, explicar, justificar i argumentar.

El model de comunicació que el professorat ha de defensar és un model democràtic, interactiu i cooperatiu. Els criteris d'aquest model de comunicació a l'aula han de ser diversos.

a) Tenir en compte la lògica de l'aprenent en la negociació de significats i donar a conèixer els criteris de valoració dels resultats, així com incloure activitats d'autoregulació dels aprenentatges. Així, l'avaluació ha de ser formadora, és a dir, s'ha d'integrar en el procés d'adquisició dels aprenentatges. Hem volgut incloure en aquest cas un esquema de lectura d'una imatge, una pintura (Vegeu la figura 3).

b) Desenvolupar el currículum a partir de problemes socials, projectes de treball o temàtiques obertes a la investigació. Aquestes tècniques trenquen l'estructura rígida de les disciplines i afavoreixen la interacció i la cooperació.

c) Afavorir el màxim d'interaccions entre l'alumnat amb la utilització d'estratègies d'ensenyament i aprenentatge diversificades, així com potenciar la cooperació que faciliti els aprenentatges entre iguals, el diàleg i la superació de conflictes. En primer lloc, cal superar les classes expositives en exclusiva o la utilització abusiva del llibre de text. La intervenció del professorat ha de ser sempre la de facilitar els aprenentatges i construir les condicions òptimes de treball per a l'alumnat. En segon terme, cal afavorir l'aprenentatge per descobriment, de tal manera que els continguts no s'han de presentar tancats, acabats, sinó com el fruit del treball de persones que els han elaborat i que tenen una determinada visió del món; s'ha de provocar les contradiccions, el conflicte $i$ el diàleg sobre els temes tractats. En tercer i últim lloc, s'ha de procurar la reconstrucció dels coneixements de l'alumnat, quines eren les seves idees prèvies i com les hem modificat, i com el mateix alumnat és conscient d'aquest fet.

d) Deixar espais de reflexió i de formació del pensament social, pensament crític creatiu, plantejant activitats per a l'empatia i per a la simulació (vegeu la figura 4). El pensament crític no es pot separar del

\section{Primer nivell d'anàlisi \\ 1. Quina acció o escena apareix? Descriu-la \\ 2. Quin és el personatge o personatges principals? \\ 3. Quins altres personatges apareixen? \\ 4. Com és l'escenari on se situa l'acció o on es desenvolupa l'escena? \\ 5. Quins colors s'utilitzen? \\ 6. Quins contrast existeix entre la llum i les ombres?}

\section{Segon nivell d'anàlisi}

7. Quines són les formes geomètriques que caracteritzen la composició?

8. Quin significat social té l'escena? Quin moment històric es representa?

9. A qui o què representa cada un dels personatges?

10. Què vol representar el lloc de l'escena?

11. Quin significat tenen els colors, les llums i les ombres?

12. Quin estil artístic correspon a aquest quadre?

\section{Tercer nivell d'anàlisi}

13. Què sabem d'aquest autor?

14. Què caracteritza la seva obra?

15. Coneixem altres pintures d'altres autors del mateix estil?

16. Com s'ha tractat aquest tema en altres períodes o estils?

Figura 3. Activitat d'autoregulació dels aprenentatges: Anàlisi de la pintura de Delacroix La Libertad guiando al pueblo, de 1831. 


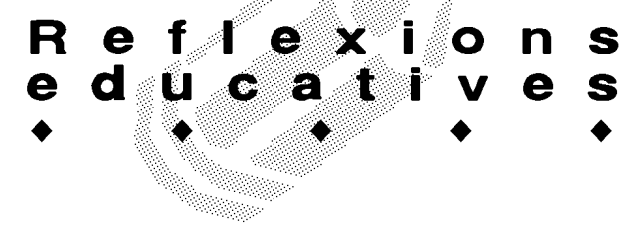

pensament creatiu, fins al punt que no pot existir l'un sense l'altre. Nickerson, Perkins i Smith (1987) afirmen en aquest sentit: "...es un tanto engañoso plantear dos estilos de pensamiento completamente diferentes - el crítico y el creativo-, porque el primero constituye necesariamente una parte del segundo. Por supuesto que lo crítico puede ser no creativo. Pero lo creativo no puede dejar de ser crítico".

D'altra banda, cal la metacognició, és a dir, ensenyar a pensar com pensem. Aquest aprenentatge és l'última clau de l'adquisició de capacitats per a l'autonomia a l'aprenentatge, és a dir, de l'aprendre a aprendre.

\section{Finalment}

L'estudi de la societat, del seu passat, del seu present i del seu futur és l'estudi del nostre món, no és un ensenyament allunyat i d'una realitat estranya, sinó que és un aprenentatge de la nostra realitat, rellevant $\mathrm{i}$ funcional per a la nostra vida quotidiana, per entendre el món, per participar de la vida democràtica i per intervenir socialment, per provocar canvis de millora social al nostre entorn.

Sembla que una gran part del professorat està entenent l'ensenyament de les ciències socials en aquest sentit. La nostra intenció en aquest treball ha estat remarcar alguns aspectes essencials del debat sobre els estudis socials. Encara que el dubte i la incertesa estan presents en molts moments, no hem de perdre de vista les qüestions bàsiques d'aquest debat.

\section{Referències bibliogràfiques}

BATLLORI, R. La teoría crítica del currículum aplicada a la geografia. L'ús de l'argumentació per a la construcció conjunta del concepte conflicte a dues aules de secundària. Tesis Doctoral. Universitat de Girona. 1998.

BENEJAM, P. i QUINQUER, D. La construcció del coneixement social i les habilitats cognitivolingüístiques. Jorba, J.; Gómez, I.; Prat, A. (eds.): Parlar i escriure per aprendre. Ús de la llengua en situació d'ensenyament-aprenentatge des de les àrees curriculars. Edita ICE de la UAB. 1998.

BENEJAM, P. i PAGĖS, J. (Coord.) Enseñar y aprender Ciencias Sociales, Geografía e Historia en la Educación Secundaria. Editorial ICE-UB/Horsori. Barcelona. 1997.

BENEJAM, P. i PAGĖS, J. (Coord.) Ciencias Sociales. Guías Praxis para el profesorado. Editorial Praxis. Barcelona. 1997.

DEWEY, J. Democràcia iescola. Editorial Eumo/Diputació de Barcelona. Vic. 1985.

ÍNSULA BARATARIA (coord.) Enseñar y aprender ciencias sociales. Algunas propuestas de modelos didácticos. Editorial Mare Nostrum. Madrid. 1994.

NICKERSON, R.S. i altres. Enseñar a pensar. Aspectos de la aptitud intelectual. Editorial Paidós/MEC. Barcelona. 1988. Pàg. 111.

TRAVÉ, G. La investigación en Didáctica de las Ciencias Sociales. Perspectivas y aportaciones desde la enseñanza y el aprendizaje de las nociones económicas. Publicaciones de la Universidad de Huelva. Huelva. 1997.

TREPAT,C. A. i COMES, P. El tiempo y el espacio en la didáctica de las ciencias sociales. Editorial Graó. Barcelona. 1998.

VVAA. Los valores y la didáctica de las ciencias sociales. Universitat de Lleida. 1998.

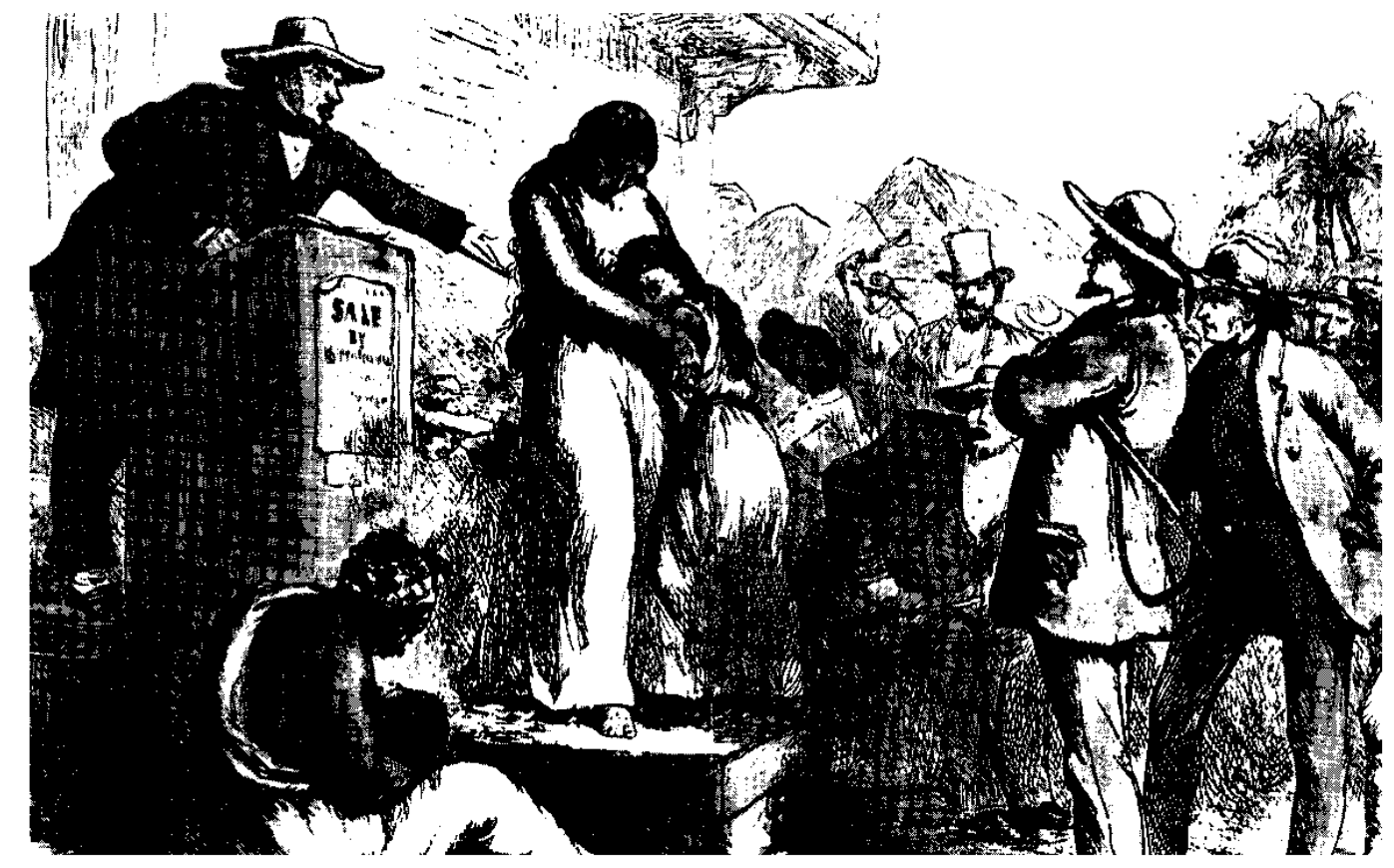

Figura 4. II-lustració d'una venda d'esclaus. Activitat sobre l'empatia: Què pensa cada personatge? 